\title{
Aplikasi Pewarnaan Bahan Alam Mangrove Pada Kain Batik Sebagai Diversifikasi Usaha Masyarakat
}

\author{
Heni Irawati*1, Novi Luthfiyana², Imra ${ }^{3}$, Triyana Wijayanti4 ${ }^{4}$ Andi Izza Naafilah5, \\ Sari Wulan6 \\ 1.4,5,6Program Studi Manajemen Sumberdaya Perairan \\ 2,3Program Studi Teknologi Hasil Perairan \\ Fakultas Perikanan dan Ilmu Kelautan Universitas Borneo Tarakan \\ *e-mail: heni.chemistry13@gmail.com
}

\begin{abstract}
Tarakan is a city located in a coastal area with the potential of mangrove forests that can flourish in the area. Mangroves can be used as natural dyes in the process of making eco-friendly batik. Natural dyes can be made by utilizing local potential. But the people of Kelurahan Gunung Lingkas does not yet have the skills in processing mangroves into batik dye. Therefore, it is very important to carry out activities that can increase community knowledge and competence in processing mangroves into natural dyeing agents in the process of making batik. The method used in this activity is training by involving partners directly in the process of making dyes and their application to fabrics. The output of this activity is the formation of a community group that can produce eco-friendly batik products. The success of this activity will improve the economy of the community in Kelurahan Gunung Lingkas of Tarakan City.
\end{abstract}

Keywords: Natural dyes, Ceriops tagal, Rhizophora apiculata, Nypa fruticans

\begin{abstract}
Abstrak
Kota Tarakan merupakan kota yang berada di daerah pesisir dengan potensi hutan mangrove yang dapat tumbuh subur di daerah tersebut. Mangrove dapat dimanfaatkan sebagai bahan pewarna alam dalam proses pembuatan batik yang ramah lingkungan. Bahan pewarna alami dapat dibuat sendiri dengan memanfaatkan potensi lokal. Namun masyarakat Kota Tarakan khususnya Kelurahan Gunung Lingkas belum memiliki pengetahuan dan keterampilan dalam mengolah mangrove menjadi bahan pewarna kain batik dan belum memiliki peralatan dan bahan yang memadai. Oleh karena itu, sangat penting dilakukan kegiatan yang dapat meningkatkan pengetahuan dan kompetensi masyarakat dalam mengolah mangrove menjadi bahan pewarna alam dalam proses pembuatan batik. Metode yang digunakan dalam kegiatan ini adalah pelatihan dengan melibatkan mitra secara langsung dalam proses pembuatan zat warna dan pengaplikasiannya pada kain. Target luaran yang diharapkan dari kegiatan ini adalah terbentuknya suatu kelompok masyarakat yang dapat menghasilkan produk kain batik ramah lingkungan. Keberhasilan dari kegiatan ini akan meningkatkan ekonomi masyarakat di Kelurahan Gunung Lingkas Kota Tarakan.
\end{abstract}

Kata kunci: Pewarna alami, Ceriops tagal, Rhizophora apiculata, Nypa fruticans

\section{PENDAHULUAN}

Pewarna alam sejak dahulu digunakan dalam industri-industri tekstil, namun dengan perkembangan zaman penggunaan bahan alam bergeser menjadi penggunaan pewarna dari bahan sintetik. Salah satu industri tekstil yang turut andil dalam penggunaan pewarna sintetik adalah industri batik, baik skala rumah tangga maupun industri besar.

Sejak penemuan pewarna sintetik, penggunaan pigmen sebagai pewarna dari bahan alam semakin menurun, meskipun keberadaannya tidak menghilang sama sekali. Pewarna sintetis memang terbukti lebih murah dan praktis sehingga lebih menguntungkan dari segi ekonomis, tetapi penggunaannya sebagai pewarna makanan, minuman dan pakaian dapat berdampak negatif. Dampak negatif yang dapat ditimbulkan dari penggunaan pewarna sintetik yaitu bersifat toksik dan karsinogenik karena kandungan logam berat dalam pewarna sintetik tidak dapat dihancurkan dalam sistem pencernaan manusia dan akan terakumulasi di dalam tubuh (Paryanto et al., 2015). 
Irawati, et al. (2018) menyatakan bahwa salah satu pewarna sintetik yang banyak digunakan dalam industri tekstil adalah kristal violet. Kristal violet maupun pewarna sintetik pada umumnya bila berada di perairan bersifat persisten karena sulit dimetabolisme oleh mikroorganisme, sehingga dapat bertahan dalam lingkungan perairan. Keberadaan pewarna sintetik dalam jumlah besar tentunya bersifat toksik bagi manusia dan biota yang hidup di sekitar perairan yang tercemar. Oleh karena itu teknologi penggunaan zat pewarna alam perlu dikembangkan lagi dalam pewarnaan tekstil terutama dalam proses pembuatan batik.

Zat pewarna alam yaitu zat warna yang berasal dari bahan-bahan alam dan pada umumnya dari hasil ekstrak tumbuhan yang lebih ramah lingkungan karena zat-zat yang terkandung dalam pewarna alam merupakan bahan organik yang mudah terurai dalam tanah. Zat warna alam untuk bahan tekstil pada umumnya diperoleh dari hasil ekstrak berbagai bagian tumbuhan seperti akar, kayu, daun, biji ataupun bunga. Salah satu tumbuhan yang mengandung zat warna alami adalah pohon mangrove. Mangrove merupakan tumbuhan pesisir yang dapat digunakan sebagai pelindung pantai dari hempasan gelombang laut penyebab abrasi.

Kota Tarakan merupakan kota yang berada di daerah pesisir dengan potensi hutan mangrove yang dapat tumbuh subur di daerah tersebut. Hutan mangrove selain memiliki fungsi ekologis, juga menghasilkan limbah terutama beberapa pohon yang sudah tidak produktif lagi dan serasah yang belum terdekomposisi.

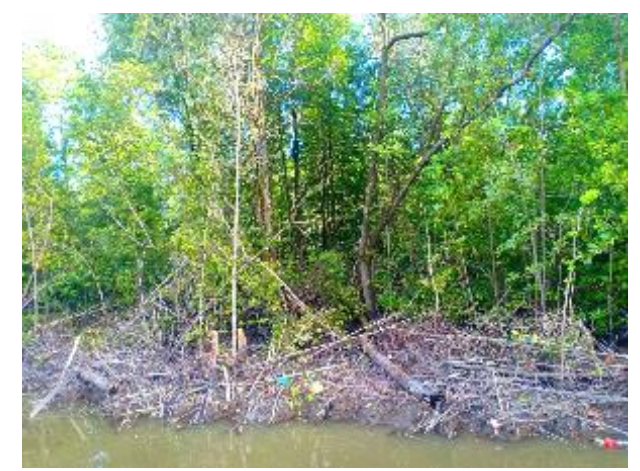

Gambar 1. Tumbuhan mangrove yang sudah mati akan menjadi limbah

Kelurahan Gunung Lingkas memiliki luas wilayah 3,19 km² (BPK Kalimantan Utara, 2015) dengan mata pencaharian penduduk daerah yang heterogen. Sebagian masyarakat Kelurahan Gunung Lingkas masih dalam kondisi ekonomi yang cukup memprihatinkan. Salah satu upaya dalam meningkatkan taraf kehidupan masyarakatnya, dibentuklah LKM Karya Mandiri Sejati yang difasilitasi oleh PNPM Mandiri Perkotaan pada tahun 2009. Lembaga ini diharapkan mampu menjadi wadah bagi masyarakat untuk meningkatkan taraf hidup masyarakat yang tidak berdaya menjadi berdaya dan masyarakat yang berdaya menjadi mandiri. Sebagai bentuk dari upaya tersebut, LKM Karya Mandiri Sejati sejak tahun 2010 telah melakukan berbagai kegiatan produktif yang melibatkan masyarakat Kelurahan Gunung Lingkas, khususnya bagi masyarakat yang ingin meningkatkan skill/keterampilan khusus.

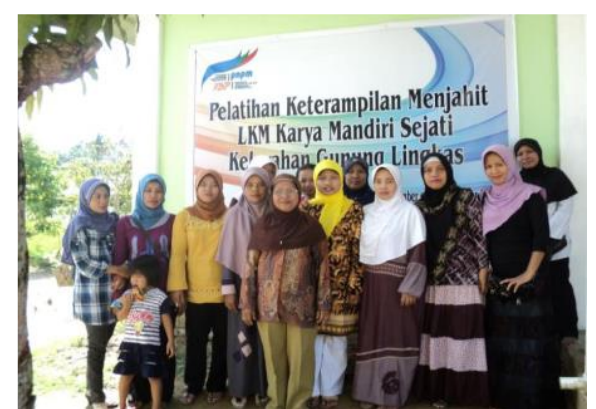

Gambar 2. Salah satu pelatihan yang telah dilaksanakan oleh LKM Karya Mandiri Sejati 
Kegiatan yang telah dilaksanakan oleh LKM Karya Mandiri Sejati diantaranya yaitu pelatihan menjahit, bengkel, membuat kue, souvenir dan lain-lain. Namun berbagai kegiatan tersebut belum semuanya yang benar-benar memanfaatkan potensi lokal yang ada di Kota Tarakan. Salah satu potensi lokal yang dimaksud adalah tanaman mangrove. Mangrove memiliki banyak manfaat secara ekonomi dalam bentuk produk pangan dan nonpangan. Ramses et al. (2018) menyatakan beberapa jenis mangrove dapat diolah menjadi minuman dan panganan. Selain itu, untuk nonpangan Menurut Sari (2016), tanaman mangrove dapat digunakan sebagai bahan baku untuk pewarnaan batik dengan cara merebus bahan yang sudah dipotong-potong dan dikeringkan. Setelah menjadi ekstrak, hasilnya ditampung dalam tangki penyimpanan kemudian dapat langsung diaplikasikan. Selanjutnya Pringgenies, et al. (2013) juga menyatakan beberapa jenis mangrove yang dapat dijadikan bahan pewarna alam untuk kain batik adalah Rhizopora mucranata, Soneratia alba, Avecenia sp., Ceriops decandra, dan Lumicera sp. Adip et al. (

Pemanfaatan mangrove sebagai pewarna alam disamping memberikan nuansa warna alami dan motif yang indah, juga dapat mengurangi pencemaran lingkungan yang menjadikan masalah besar bagi lingkungan sekitarnya. Pemanfaatan mangrove sebagai pewarna alami juga berperan dalam eksploitasi ekosistem mangrove tanpa harus merusak. Hal ini dikarenakan bagian mangrove yang dimanfaatkan sebagai pewarna adalah limbah atau bagian tanaman yang sudah tidak terpakai bahkan yang sudah hampir mati. Selain ramah lingkungan, bahan bakunya terbilang murah, hanya saja prosesnya memakan waktu lama. Pembuatan selembar batik dengan warna alam memerlukan waktu sebulan. Sedangkan proses pembuatan batik dengan pewarna kimia sedikit lebih mudah, hanya memakan waktu seminggu untuk selembar batik (Martuti et al., 2017).

Pembuatan batik dengan pewarnaan alam dari tanaman mangrove sangat mungkin dilakukan di Kota Tarakan. Hal ini dikarenakan oleh banyaknya potensi tumbuhan mangrove yang sangat subur, yang selama ini belum dimanfaatkan peran dan fungsinya sebagai sumber daya potensi lokal dari Kota Tarakan. Pembuatan batik dengan pewarnaan mangrove sangatlah cocok untuk dibuat dan dikembangkan karena memiliki potensi usaha yang cukup besar untuk kemajuan daerah itu dan apabila dapat dikelola dengan baik maka fungsi dan manfaat tanaman mangrove dapat dirasakan berguna bagi masyarakat sehingga ekosistem tanaman mangrove itu sendiri dapat menjadi lestari dikarenakan punya manfaat ekonomis yang terasa bagi masyarakat di daerah Kota Tarakan.

\section{METODE}

Kegiatan PKM dilaksanakan di Kelurahan Gunung Lingkas Kota Tarakan pada tanggal 28 Juli 2019. Kegiatan ini bermitra dengan LKM Karya Mandiri Sejati Kelurahan Gunung Lingkas.

Pendekatan yang dilaksanakan untuk mencapai tujuan yang diharapkan bersama mitra adalah sebagai berikut:

a. Koordinasi dan sosialisasi kegiatan bertujuan untuk menggali informasi terkait permasalahan mitra dan memberikan gambaran mengenai kegiatan yang akan dilaksanakan

b. Metode pendidikan bagi mitra tentang manfaat dan fungsi tanaman mangrove yang dapat dijadikan sebagai bahan pewarnaan batik yang kemudian dapat menjadi solusi untuk meningkatkan pendapatan masyarakat.

c. Metode demonstrasi pembuatan zat warna alam dengan bahan pewarna mangrove sehingga peserta dapat secara mudah untuk membuat dan mengerjakannya. Demonstrasi ini dilakukan secara terstruktur oleh tim kegiatan PKM beserta mahasiswa. Metode demonstrasi bertujuan agar peserta pelatihan dapat mengamati langsung proses pengerjaan dan pembuatannya dari awal hingga akhir.

d. Memberikan metode latihan dan praktik dalam pembuatan bahan pewarna mangrove. 
e. Memberikan pendampingan dan bimbingan yang berkesinambungan dalam pembuatan batik berbahan pewarna mangrove.

\section{HASIL DAN PEMBAHASAN}

Program Kemitraan Masyarakat "Aplikasi Pewarnaan Bahan Alam Mangrove pada Kain Batik sebagai Diversifikasi Usaha Masyarakat Kelurahan Gunung Lingkas Kecamatan Tarakan Timur Kota Tarakan" diawali dengan survei lapangan untuk mengetahui permasalahan mitra dan ketersediaan sumberdaya alam yang akan dimanfaatkan. Setelah itu dilakukan rapat bersama mitra agar terbentuk suatu kesepakatan bersama untuk mengadakan suatu pelatihan. Berdasarkan hasil survei yang telah dilakukan, dapat diketahui bahwa sebagian mitra telah mengetahui teknik membatik, namun belum mengetahui bagaimana cara membuat bahan pewarna dari limbah mangrove. Sehingga mitra sangat antusias untuk mengikuti pelatihan aplikasi pewarnaan bahan alam mangrove pada kain batik.

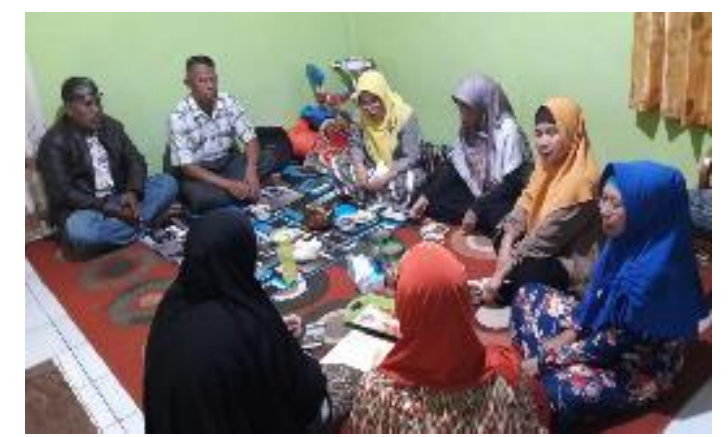

Gambar 3. Rapat bersama mitra membahas persiapan pelatihan

Pembuatan bahan pewarna alam pada kegiatan ini menggunakan bahan baku berupa limbah daun Rhizophora apiculata, kulit batang Ceriops tagal dan limbah dari kulit buah Nypa fruticans. Bagian dari buah nipah (Nypa fruticans) yang dimanfaatkan pada kegiatan ini adalah limbah kulit buahnya saja, sedangkan Rhizophora apiculata diambil pada bagian daunnya dan Ceriops tagal diambil bagian kulit batang pohon nya. Menurut Pringgenies et al. (2013), bagian dari tumbuhan yang dapat dijadikan sebagai bahan baku pewarna adalah batang, kayu, akar, daun, bunga, kulit dan buah. Rosyada et al. (2018) menyatakan masyarakat desa Bakau Besar Laut telah memanfaatkan mangrove sebagai zat pewarna.

Bahan baku yang digunakan dalam kegitaan ini diambil dari sumberdaya pesisir yang ada di sekitar Kota Tarakan. Nipah (Nypa fruticans) diambil dari pesisir Pantai Amal Lama Kota Tarakan, sedangkan daun Rhizophora apiculata dan kulit batang Ceriops tagal diambil dari limbah sisa pembukaan lahan mangrove di Kelurahan Karang Anyar Pantai Kecamatan Tarakan Barat untuk pemukiman masyarakat. Sehingga kegiatan PKM ini ramah lingkungan karena proses pemanfaatan sumberdaya alam pesisir untuk bahan pewarnaan dilakukan tanpa merusak sumberdaya alam yang ada.

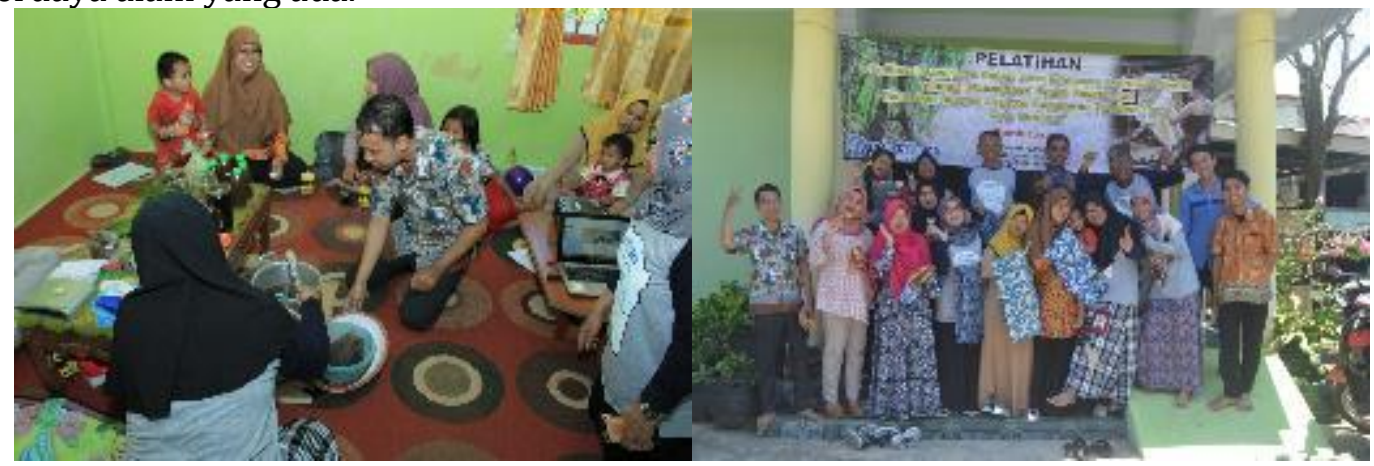

a)

b) 
Gambar 4. Pelatihan pewarnaan kain dari bahan mangrove: a) pembuatan ekstrak warna dari mengrove, dan b) Tim PKM bersama mitra

Proses pembuatan bahan pewarna mangrove untuk kain batik dimulai dengan pengambilan ekstrak mangrove yang dilakukan dengan cara merebus bahan baku berupa limbah daun Rhizophora apiculata, kulit batang Ceriops tagal dan limbah dari kulit buah Nypa fruticans, kemudian merendam bahan kain ke dalam larutan ekstrak selama 15-30 menit sesuai Pringgenies et al. (2013). Setelah direndam, kain dikering-anginkan di tempat yang teduh agar tidak terpapar oleh cahaya matahari secara langsung. Menurut Annisa (2018) kain batik tidak boleh dijemur di bawah sinar matahari secara langsung karena pemaparan cahaya matahari secara langsung dapat mengakibatkan berubahnya warna kain dan dapat menyebabkan kain batik yang dijemur menjadi kusam.

Perendaman dilakukan sebanyak 6-7 kali. Hal ini dilakukan agar warna yang dihasilkan dapat maksimal dan tidak pudar saat dibilas. Setelah proses perendaman, dilakukan fiksasi menggunakan 3 macam fiksator berbeda dengan tujuan agar kain yang telah diberi bahan pewarna alam tidak mudah luntur dan dapat diperoleh 3 jenis warna yang berbeda. Sedangkan jenis kain yang digunakan adalah katun. Hasil pewarnaan kain menggunakan kulit batang Ceriops tagal dapat dilihat pada Gambar 5.

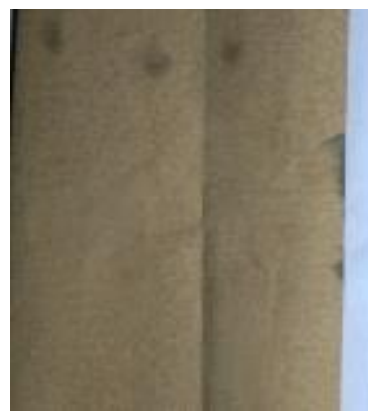

a)

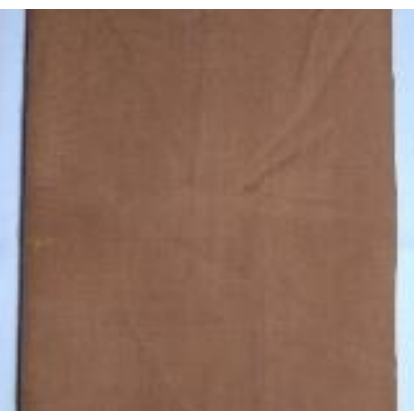

b)

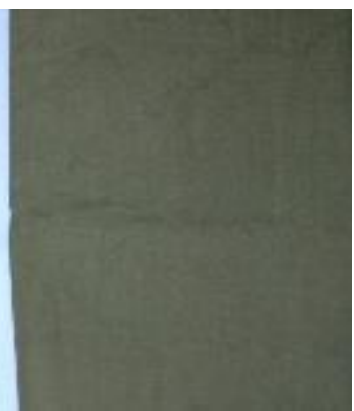

c)

Gambar 5. Hasil pewarnaan menggunakan kulit batang Ceriops tagal dengan fiksator: a) tawas, b) kapur gamping, dan c) tunjung

Hasil fiksasi yang ditunjukkan dari 3 macam fiksator menghasilkan 3 jenis warna yang berbeda pula. Adapun 3 macam fiksator yang digunakan adalah tawas, kapur gamping dan tunjung. Warna yang dihasilkan pada fiksator tawas adalah cokelat muda, warna merah bata untuk fiksator kapur gamping dan warna cokelat tua gelap untuk fiksator tunjung (Gambar 6).

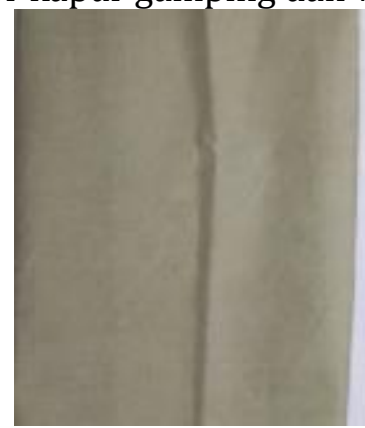

a)

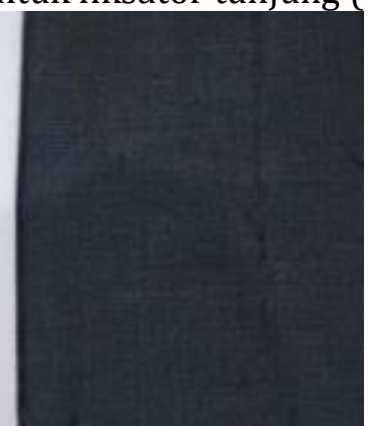

c)

Gambar 6. Hasil pewarnaan menggunakan daun Rhizophora apiculata dengan fiksator: a) tawas, b) kapur gamping, dan c) tunjung

Hasil fiksasi yang ditunjukkan dari 3 macam fiksator menghasilkan 3 jenis warna yang berbeda pada pewarnaan menggunakan daun Rhizophora apiculata. Warna yang dihasilkan pada 
fiksator tawas adalah abu muda, warna mustard untuk fiksator kapur gamping dan warna navy gelap untuk fiksator tunjung (Gambar 7).

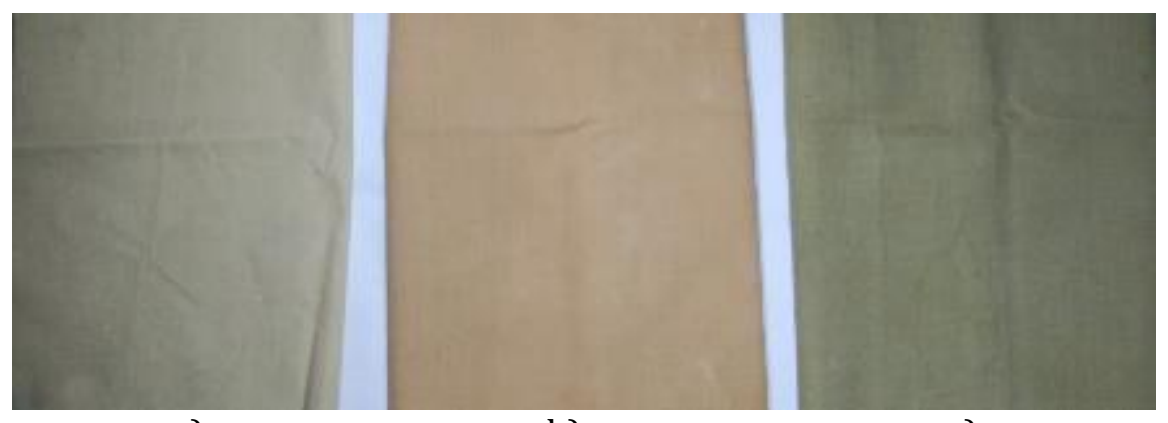

a)

b)

c)

Gambar 7. Hasil pewarnaan menggunakan limbah dari kulit buah Nypa fruticans dengan fiksator: a) tawas, b) kapur gamping, dan c) tunjung

Hasil fiksasi yang ditunjukkan dari 3 macam fiksator menghasilkan 3 jenis warna yang berbeda pada pewarnaan menggunakan limbah dari kulit buah Nypa fruticans. Warna yang dihasilkan pada fiksator tawas adalah cokelat susu, warna cokelat pramuka untuk fiksator kapur gamping dan warna krem kehijauan (khaki) untuk fiksator tunjung.

Berdasarkan uji kelunturan yang dilakukan, penggunaan fiksator tunjung terbukti lebih awet dan tahan luntur. Pewarnaan alam dari bahan mangrove secara umum menghasilkan warna lebih muda pada penggunaan fiksator tawas, warna terang pada fiksator kapur gamping dan warna gelap pada fiksator tunjung. Warna yang dihasilkan pun dapat lebih bervariasi jika dilakukan pencampuran bahan baku maupun fiksator.

Pewarnaan kain batik dengan menggunakan bahan alam memberikan hasil pewarnaan yang baik, lebih aman, sehat dan nyaman digunakan tanpa khawatir timbulnya efek samping sebagaimana dengan penggunaan bahan pewarna sintetik. Mangrove jenis nipah diketahui memiliki sifat antibakteri (Imra et al. 2016), sehingga diharapkan pewarnaan dari nipah ini memberikan efek kesehatan bagi tubuh ketika menggunakan dan dapat mencegah serangan bakteri dari aktivitas yang dijalankan di luar rumah. Selain itu, penggunaan bahan pewarna alami juga lebih ramah lingkungan karena tidak menimbulkan pencemaran pada lingkungan perairan khususnya. Hal ini sesuai dengan pernyataan Alamsyah (2018) bahwa batik yang dibuat menggunakan pewarna alami akan membuat nyaman bagi konsumen pemakai dan dijamin tidak menimbulkan kekhawatiran akan timbulnya alergi pada kulit. Batik yang menggunakan pewarna alami juga banyak diminati oleh konsumen mancanegara, sehingga memiliki nilai ekonomis yang sangat tinggi dan berpotensi untuk dijadikan sumber penghasilan tambahan bagi masyarakat kelurahan Gunung Lingkas.

Kain batik dengan pewarna alam memiliki kelebihan keamanan, kenyamanan dan ramah lingkungan. Proses pembuatannya cukup mudah. Biaya yang dikeluarkan juga murah karena bahan baku yang digunakan cukup dengan memanfaatkan potensi alam yang ada di sekitar kita. Namun, dalam proses pembuatannya, diperlukan kesabaran dan keuletan yang lebih besar bila dibandingkan dengan penggunaan pewarna sintetik. Pewarnaan bahan alam juga memerlukan waktu yang lebih lama. Mengingat kualitas dan dampak yang akan ditimbulkan, kekurangan tersebut bukanlah kendala ataupun hambatan untuk tetap memaanfaatkan potensi sumberdaya lokal dengan tetap menjaga kelestariannya.

Luaran yang telah dihasilkan dalam kegiatan ini berupa terbentuknya 1 kelompok keswadayaan masyarakat (KSM) yang siap bekerja memproduksi kain batik dengan menggunakan pewarna alam yang ada di sekitar wilayah Kota Tarakan sebagai kawasan pesisir. Kelompok masyarakat ini masih rintisan dan pengelolaannya di bawah LKM Karya Mandiri Sejati Kelurahan Gunung Lingkas Kota Tarakan. 


\section{KESIMPULAN}

Aplikasi pewarnaan bahan alam mangrove pada kain batik yang telah dilakukan oleh masyarakat Kelurahan Gunung Lingkas Kecamatan Tarakan Timur Kota Tarakan sangat memberikan manfaat dalam menggali potensi sumberdaya alam kawasan pesisir Kota Tarakan. Kegiatan ini juga dapat meningkatkan taraf ekonomi masyarakat setempat jika dikelola dengan baik.

\section{UCAPAN TERIMA KASIH}

Kegiatan PKM didanai oleh DIPA LPPM Universitas Borneo Tarakan. Oleh karena itu, tim pelaksana mengucapkan terima kasih yang sebesar-besarnya kepada LPPM UBT atas bantuannya dan kepada mitra LKM Karya Mandiri Sejati Kelurahan Gunung Lingkas atas kerjasamanya. Semoga kegiatan ini dapat terus berlanjut dengan hasil yang lebih baik.

\section{DAFTAR PUSTAKA}

Alamsyah. (2018). Kerajinan Batik dan Pewarnaan Alami. Endogami: Jurnal Ilmiah Kajian Antropologi, 1(2), 136-148.

Annisa, U. (2018). Batik Tulis dengan Pewarna Remazol Di Home Industry Candi Desa Candimulyo Kecamatan Dolopo Kabupaten Madiun. Jurnal e-Craft, 7(6), 561-572.

Imra., Kustiariyah, T., dan Desniar. (2016). Aktivitas Antioksidan dan Antibakteri Ekstrak Nipah (Nypa fruticans) Terhadap Vibrio sp. Isolat Kepiting Bakau (Scylla sp.). Jurnal Pengolahan Hasil Perikanan Indonesia, 19(3), 241-250.

Irawati, H., Aprilita, N. H., dan Sugiharto, E. (2018). Adsorpsi Zat Warna Kristal Violet Menggunakan Limbah Kulit Singkong (Manihot esculenta). Jurnal Berkala MIPA, 25(1), 17-31.

Martuti, N. K. T., Soesilowati, E., dan Na'am, M. F. (2017). Pemberdayaan Masyarakat Pesisir Melalui Penciptaan Batik Mangrove. ABDIMAS, 21(1), 65-74.

Paryanto, Kwartiningsih, E., Agung, W., Pranolo, S.H., Haningtyas, V., Hidayat, R., dan Roy, I. (2015). Pengambilan Zat Warna Alami dari Buah Mangrove Spesies Rhizophora mucronata untuk Pewarna Batik Ramah Lingkungan. Jurnal Purifikasi, 15(1), 33-40.

Pringgenies, D., Supriyantini, E., Azizah, R., Hartati, R., Irwani dan Radjasa, O.K. (2013). Aplikasi Pewarnaan Bahan Alam Mangrove untuk Bahan Batik sebagai Diversifikasi Usaha Di Desa Binaan Kabupaten Semarang. Majalah Info, XV(1), 1-10.

Ramses., Erwin, A., dan Ramdani. (2018). Inovasi Minuman dan Panganan Berbahan Baku Bidara Laut (Ximenia Americana) dan Mangrove dari Pesisir Kota Batam. Dinamisia, 2(2), 197204.

Rosyada, A., Sofwan, A., Muflihati. (2018). Pemanfaatan Tumbuhan Mangrove oleh Masyarakat Desa Bakau Besar Laut Kecamatan Sungai Pinyuh Kabupaten Mempawah. Jurnal Hutan Lestari, 6(1), 62-70.

Sari, R. (2016). Penggunaan Mangrove untuk Meningkatkan Pendapaan Ekonomi Rumah Tangga. Jurnal Pengabdian Kepada Masyarakat, 22(4), 10-15. 